\title{
Equipment and Energy Usage in a Large Teaching Hospital in Norway
}

\author{
Tarald Rohde ${ }^{\mathbf{1}^{*}}$ and Robert Martinez ${ }^{2}$ \\ ${ }^{1}$ SINTEF, Technology and Society, Hospital Planning, Oslo, Norway \\ ${ }^{2}$ Norconsult as, Sandvika, Norway
}

Submitted October 2014. Accepted for publication April 2015.

\begin{abstract}
This article presents a study of how equipment is used in a Norwegian University hospital and suggests ways to reduce hospital energy consumption. Analysis of energy data from Norway's newest teaching hospital showed that electricity consumption was up to $50 \%$ of the whole-building energy consumption. Much of this is due to the increasing energy intensity of hospital-specific equipment. Measured power and reported usage patterns for equipment in the studied departments show daytime energy intensity of equipment at about $28.5 \mathrm{kBTU} / \mathrm{ft}^{2}$ per year $\left(90 \mathrm{kWh} / \mathrm{m}^{2}\right.$ per year), compared to building code standard value of only $14.9 \mathrm{kBTU} / \mathrm{ft}^{2}\left(47 \mathrm{kWh} / \mathrm{m}^{2}\right.$ per year) for hospitals. This article intends to fill gaps in our understanding of how users and their equipment affect the energy balance in hospitals and suggests ways in which designers and equipment suppliers can help optimize energy performance while maintaining quality in the delivery of health services.
\end{abstract}

Keywords: hospital, energy, HVAC, efficiency, medical equipment, MRI, CT

\section{INTRODUCTION}

Hospitals are large energy consumers, and much of this consumption is due to the increasing energy intensity of hospital-specific equipment [1]. This article intends to fill gaps in our understanding of how users and their equipment affect the energy balance in hospitals, and suggests ways in which designers and equipment suppliers can help optimize energy performance while maintaining quality in the delivery of health services. The study is based on the authors' work in the Low Energy Hospital (2010-2014) project supported by the Norwegian Research Council. This article builds on previously published work by the authors on the potential for energy reduction in hospitals by delivering energy on demand, by exploiting variation in activity levels in different parts of the hospital.[2]

Hospital building construction and heating, ventilating and air-conditioning (HVAC) systems are relatively better documented compared to knowledge of actual power and energy consumption of equipment in modern hospitals [3]. In hospitals, it is the staff

*Corresponding author: Tarald Rohde, SINTEF, Technology and Society, Hospital Planning, Postboks 124, Blindern, NO-0314 Oslo, NORWAY. Location: Forskningsveien 1, 0373 Oslo. Phone 004795051745. Telefax: +47 22067909. E-mail: Tarald.Rohde@sintef.no. Other author: robert. martinez@norconsult.no. 
and patients' use of equipment and lighting which largely drives the demand on the electric grid, through direct energy demand and through the need to dissipate waste heat by the heating, cooling and ventilation systems [4].

\subsection{Why Study Equipment Energy Consumption?}

Most hospital-specific equipment is the domain of medical professionals, not engineers or architects [5]. Without more detailed knowledge of equipment usage, HVAC engineers resort to standardized values and/or nominal electrical power ratings for sizing and designing [6]. In large and complex hospitals, these practices can lead to suboptimal sizing of the electrical, heating and cooling systems, and missed opportunities for storing and recycling waste heat.

To provide a better design basis, our study investigated the share of total electrical load due to hospital equipment, the energy-intensity of equipment types and hospital areas, equipment usage patterns, and whether the equipment being used in an energyefficient way.

\subsection{Trends in Hospital Equipment Energy Consumption}

Analysis of energy data from Norway's newest large university teaching hospital ${ }^{1}$ in the Oslo area showed that electricity consumption to fans, pumps, lighting and user equipment ${ }^{2}$ varied between 51,7 and $61,2 \mathrm{kBTU} / \mathrm{ft}^{2}$ per year $\left(163\right.$ and $190 \mathrm{kWh} / \mathrm{m}^{2}$ per year). This represents up to $50 \%$ of the whole-building energy use, and is an increase over older less equipped hospitals. Waste heat from much of this electrical energy must then be removed from the room, which leads to an additional cooling energy load, even in the cold Norwegian climate [7]. Typical energy flows are diagrammed in Figure 1 below, showing typical distribution of waste heat from hospital medical equipment with an annual electrical energy input of $3412 \mathrm{kBTU}(1000 \mathrm{kWh})$.

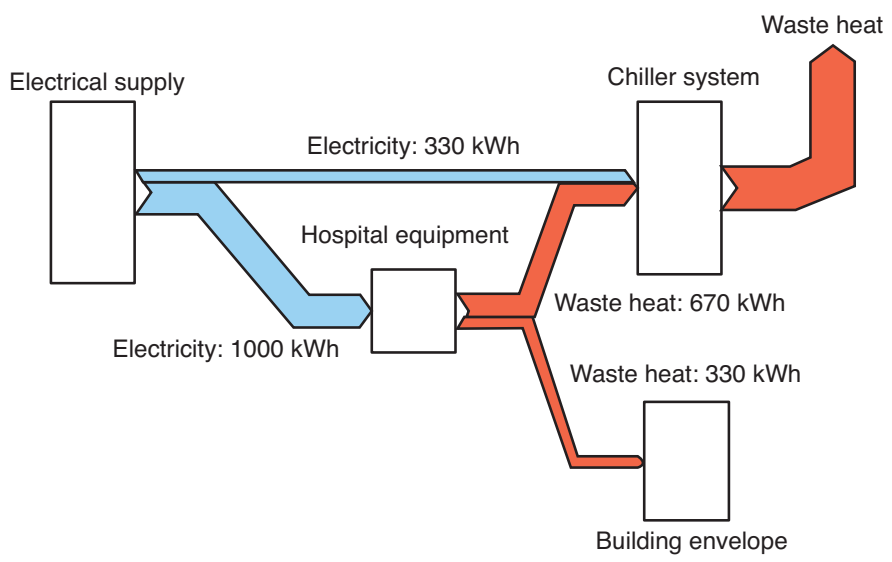

Figure 1. Energy flow diagram for hospital equipment with data of annual energy consumption.

\footnotetext{
${ }^{1}$ Akershus University Hospital (AHUS), 570 bed hospital, fully opened 2009, 1,474,600 ft ${ }^{2}\left(137,000 \mathrm{~m}^{2}\right)$. ${ }^{2}$ User equipment is used in Norway to separate it from equipment directly connected to the body of the building.
} 
Electronic devices now consume more electricity in U.S. buildings than any other single end-user, including space heating and cooling, water heating, and lighting [8]. In their Hospital energy benchmarking study, the Lawrence Berkeley National Laboratory concludes that miscellaneous equipment and plug loads are important energy consumers in hospitals [9].

Another study by the US Department of Energy (DOE) Building Technologies Program [10] noted growing energy consumption of medical imaging equipment due to "higher power systems and steady installed base growth". Installed equipment energy density per unit area is increasing due to increased processing capacity, more screens and screen area, and more treatments involving new electrical diagnostic equipment.

\subsection{Classification of Hospital Equipment}

Equipment is divided into four main categories in hospitals in Norway:

- $\quad$ Medical technical equipment (MTE)

- $\quad$ Building equipment (BE)

- Information, computer, telecom (ICT) equipment

- $\quad$ Furniture (this category is not in scope because it does not involve energy use.)

\subsubsection{Medical Technical Equipment}

MTE may be divided into large and small MTE, and non-electrical surgical instruments, etc. In large MTE, one finds medical imaging equipment (MIE), including Magnetic Resonance Imaging (MRI), Positron Emission Tomography (PET), Computer Tomography (CT), and X-ray and fluoroscopes for diagnosis. These are large, expensive items housed in special rooms, usually with connections for water cooling to supplement air cooling. Notably, biochemical laboratories have large equipment types which are not MIE.

The other sub-category of smaller medical technical equipment (SMTE) has a much longer and more varied list including monitors, analyzers and therapeutic devices. These are smaller air-cooled devices located in many rooms throughout the hospital, which reject their waste heat to the room air. These devices have short startup times and draw much less power, but in a much greater quantity than large MTE. Strictly speaking, an ultrasound apparatus is an imaging device, but shares many of the characteristics of SMTE and is therefore grouped in the SMTE category.

\subsubsection{Building Equipment}

Building equipment is typically autoclaves, decontaminators, washing machines, ventilated hoods, fume cupboards and safety cabinets. Much of this equipment has traditionally been integrated in the building's walls and floors, and integrated with the building's HVAC systems such as heating supply and the ventilation ductwork for air exhaust.

\subsubsection{ICT Equipment}

More and more MTE includes ICT devices, but the category ICT equipment here is limited to computers and laptops, screens and servers in server rooms without direct clinical functions. Server rooms are an especially large consumer of both electrical and 
cooling energy in modern hospitals. The reduction of energy use by ICT equipment is an established research field and is not in focus for the equipment studied in the Low Energy Hospitals project.

\section{METHOD}

Three types of data were collected in this study: equipment inventory, equipment usage, and power and energy consumption. Unless otherwise specified, all the data were collected in Rikshospitalet, the country's national hospital, opened in Oslo in 2001. Rikshospitalet is a 580-bed, full-service university hospital with a floor area of $2,070,000 \mathrm{ft}^{2}\left(192,500 \mathrm{~m}^{2}\right)$.

\subsection{Equipment Inventory Data}

Equipment inventory data for this paper was gathered from existing hospital databases and the ICT department of the South-East Health region ${ }^{3}$. The databases hold the inventory of hospital equipment, by type and location, as well as the floor area of various hospital departments. Data for autoclaves/decontaminators/ventilated benches were collected from the hospital's technical division. Data for ICT equipment were sourced from the hospitals ICT subcontractor. Of a total inventory of 18,700 separate electrical medical technical items, the ICT equipment category dominates with 11,400 separate items. In the category of BE, there were 46 biological safety cabinets, 85 decontaminators, and 17 autoclaves. Excluded from the analysis due to lack of data were 'household equipment' like refrigerators and dishwashers. Ultra freezers were also excluded. ${ }^{4}$

As part of this study, the supplier datasheet were gathered for the equipment with electrical power draw over $500 \mathrm{~W}$, and the average power levels in continuous use and in standby were determined based on this information. This analysis showed a normal distribution curve for installed power, led by building equipment categories for autoclaves, decontaminators, and steam generators. Large imaging MTE was in second place, followed by food preparation and other kitchen equipment. In the middle of the distribution was laboratory and analysis equipment. Patient monitoring equipment had relatively low total installed power.

\subsection{Equipment Usage Data}

Detailed room-level equipment usage data for MTE in Rikshospitalet were collected via responses to questionnaires that were distributed to key personnel. The study focused on the following typical, energy-intensive hospital areas:

- Radiology department

- $\quad$ Surgical department (Operating 1) with 8 surgical units

- Intensive care unit (ICU) for the thorax department with 11 beds

- $\quad$ Bed ward in the cardiology department

- Medical biochemistry laboratory

- $\quad$ Surgical outpatient/day treatment department.

${ }^{3}$ The state-owned hospital sector is divided into four regions, of which the South-East region is the largest. ${ }^{4}$ Ultra freezers must be turned on always and did not have a part in this study. 
Rikshospitalet has three surgical units and one day surgery unit. We measured electrical power to what is called surgical unit 1 serving thorax and heart surgery, gastro surgery, and transplantations. The measured switchboards covered power supply to their respective departments with the exception of angiography usage, which was excluded from the Radiology department. For the medical biochemistry laboratory, the switchboard served about $2 / 3$ of that department's floor area.

Equipment usage patterns in most of these departments may be generalized to other large hospitals with similar clinical functions. Results for the medical biochemistry laboratory, however, may not be applied to other laboratory types such as microbiology, pathology and immunology which have different equipment and/or usage patterns. Questionnaire answers from professionals in all the above departments helped to determine the actual inventory of medical equipment, how it was used, and when it was used.

\subsection{Equipment and Department Power and Energy Data}

A subset of typical hospital areas was selected for a more thorough study in this paper, as these areas are most common to all large hospitals (see section 3.1). The electrical power for each target area was measured at the switchboard, at a specific time: midweek between $10 \mathrm{am}$ and noon. These data were supplemented with additional data from the energy management system of another hospital, Akershus University Hospital (AHUS).

In the switchboard room of the medical biochemistry laboratory, the measurements were logged at 1 minute intervals for an entire week to compute corresponding energy use. This was done at Rikshospitalet. Total hospital energy usage data were collected from AHUS hospital on the outskirts of Oslo. Hospital wide energy data and equipment usage reports could not be combined for the same hospital, due to the lack of detailed energy metering at the slightly older Rikshospitalet. To compensate and correct for this, daytime electrical power levels were measured at AHUS.

\section{RESULTS AND ANALYSIS}

\subsection{Reported Activity Levels for Hospital Departments}

An earlier report [11] from this research project concluded that there was a large variation in reported activity levels over the course of a week and also between department areas. Most of the areas are in use only during ordinary office hours for five working days of a week. Only some areas are in full use 24 hours per day, 7 days a week. The project recorded the percentage of the day-staff on duty during evenings, nights and weekends. A survey of studies concerned with user activity and energy consumption underlines the importance of correct estimates of after-hours usage [12].

Staffing levels at bed wards was reduced to $20-30 \%$ in the evening and to $10-15 \%$ at night. For radiology, the evening shift was $18 \%$ of the dayshift; at night, it was close to zero; and in the daytime on weekends it was $7 \%$. For the medical biochemistry laboratory, it is $7 \%$ in evenings, $3 \%$ at nights, and $13 \%$ during the day on weekends.

Table 1 shows activity in terms of equipment usage relative to all equipment registered at the department, in medical biochemistry and radiology. The usage pattern 
Table 1. Reported use of MTE relative to all equipment registered in the department for medical biochemistry and radiology, recorded in 2013.

\begin{tabular}{|c|c|c|c|c|c|c|c|}
\hline & \multirow[b]{2}{*}{$\begin{array}{c}\text { Constant } \\
\text { use }\end{array}$} & \multicolumn{3}{|c|}{ Weekdays } & \multicolumn{3}{|c|}{ Weekends } \\
\hline & & $\begin{array}{c}\text { Daytime } \\
0800-1600\end{array}$ & $\begin{array}{c}\text { Afternoon } \\
\text { /evening } \\
1600-0000\end{array}$ & $\begin{array}{c}\text { Night } \\
\text { 0000-0800 }\end{array}$ & $\begin{array}{c}\text { Daytime } \\
0800-1600\end{array}$ & $\begin{array}{c}\text { Afternoon } \\
\text { /evening } \\
1600-0000\end{array}$ & $\begin{array}{c}\text { Night } \\
0000-0800\end{array}$ \\
\hline \multicolumn{8}{|l|}{ Medical } \\
\hline Biochemistry & $40.2 \%$ & $38.5 \%$ & $10 \%$ & $10 \%$ & $2.10 \%$ & $0.80 \%$ & $0 \%$ \\
\hline Radiology & n.r. ${ }^{*}$ & $93.5 \%$ & $25.8 \%$ & $22.6 \%$ & $38.70 \%$ & $25.80 \%$ & $3.20 \%$ \\
\hline
\end{tabular}

*not registered

is similar to what was found in staff schedules, but with some important exceptions. In the medical biochemistry laboratory, as much as $40 \%$ of the MTE runs 24/7. Laboratory equipment is left running unattended; probably to avoid delays with restarting and calibrating the equipment after it has been turned off. The percentages for radiology are when the different radiology laboratory rooms are in use. It is a marked fall from daytime in weekdays to other times of the day and week. The sum is lower than $100 \%$ because some of the registered equipment is no longer in use. Particularly for medical biochemistry, the equipment data base still had many items that were not in use any more.

The results from the other departments that registered their use of equipment showed that the cardiology ward is open around the clock, but the reported data show large variation in actual activity. When patients are under constant monitoring, about $25 \%$ of the related MTE is used 24/7. At the time of responding to the questionnaire, the ward did not have any such patients; therefore only 2-3\% of the MTE was is use. Under normal conditions, according to the survey response, $24 \%$ of the MTE is used in daytime, $10 \%$ is seldom used, and $13 \%$ is hardly used at all ${ }^{5}$.

The equipment in the surgical suites is active while the suite is in use. The suites in Rikshospitalet have presence detection sensors. Analysis showed that over the course of one working week, the suites were occupied $70 \%$ during daytime and afternoon, and only $20 \%$ during night.

The ICU is open around the clock, but the reported data show large variation in actual activity. We visited the ICU to record activity levels and found that 4 of 11 beds were not in use; among them the isolation room and the unit had only one respiratory patient. The reported normal level of activity for respiratory care with $\mathrm{ECMO}^{6}$ was 260 days/nights in a year. There were 3 infusion pumps in use, but the available capacity was up to 10 such pumps per bed.

The ICU also had capability for 24-hour dialysis. Beside each bed, there is a column for equipment with 24 electrical sockets and additional 6 sockets in the wall; this installed capacity gives some indication of the potential electrical power draw in these

\footnotetext{
${ }^{5}$ Patient lifts were reported hardly used at all, while infusion pumps were seldom used. ${ }^{6}$ Extracorporeal membrane oxygenation (commonly abbreviated ECMO) is an extracorporeal technique of providing both cardiac and respiratory support oxygen to patient.
} 


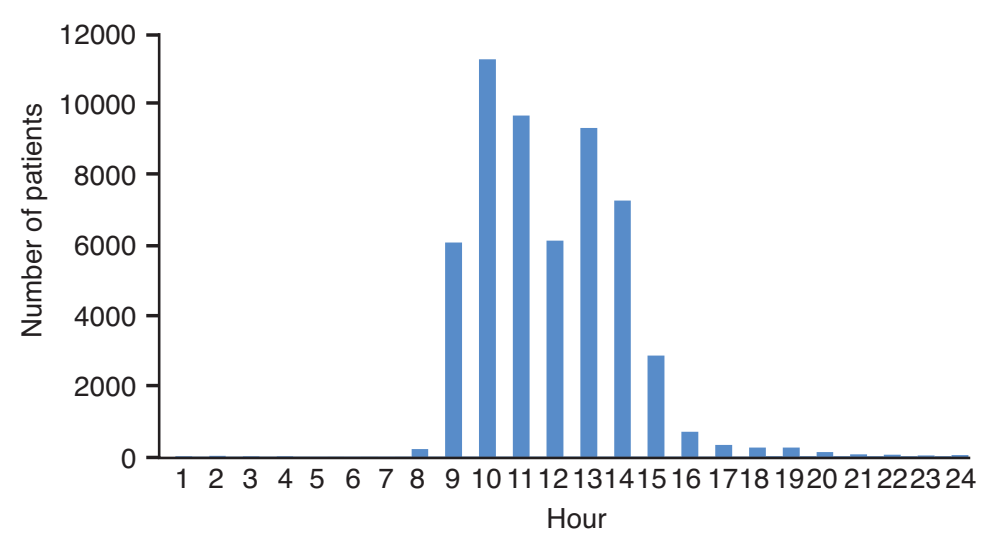

Figure 2. Outpatient consultations/treatments in during a day in a surgical outpatient/day care department, 2010.

hospital areas. At the time of our visit, the ICU equipment usages were probably below average, indicating that technical support for parts of a hospital must handle great variance in the intensity of activities.

Figure 2 describes the activity in the surgical out-patient/day care clinic. Patients started to arrive around 9 AM; there is a peak in activity at 10-11 AM; activity falls quickly after $2 \mathrm{PM}$; and it is closed after $5 \mathrm{PM}$.

\subsection{Reported Usage Levels of Medical Technical Equipment (MTE)}

The reported usage levels for MTE in different departments are shown in Table 2. Cardiology is a ward where patient's vital signs are monitored around the clock; but at the time of power measurement, there were no such patients. Most hospital bed wards are places where patients wait for diagnosis and treatments done elsewhere. If this is the case, then there must be another explanation for the relatively high levels of energy consumption in the ward areas of AHUS. One possible explanation is the amount and intensity of "household" activities requiring electrical energy in such wards. At Rikshospitalet, hot food is served to the patients on special serving trays which keep the food warm. That hospital also has traditional ward kitchens with industrial type refrigerators, dishwashers, coffee machines and numerous ICT equipment, such as copy machines and LCD screens.

The low usage-percentages of MTE in the surgical outpatient/day care department were as expected. Different patients require different examinations and treatments, involving different rooms and equipment. One may conclude that even in a major national-level hospital such as Rikshospitalet, the patient population is not big and diverse enough for simultaneous usage of a large variety of MTE.

The reported usage rate of MTE equipment is high in the Radiology Department, and even higher usage levels were recorded in the medical biochemistry laboratory. 
Table 2. Use of medical technical equipment in six departments at Rikshospitalet, Oslo, 2013, percentage of all registered equipment in the departments.

\begin{tabular}{lcccccc}
\hline & $\begin{array}{c}\text { Surgical } \\
\text { outpatient/day } \\
\text { care department }\end{array}$ & $\begin{array}{c}\text { ICU, } \\
\text { thorax }\end{array}$ & $\begin{array}{c}\text { Cardiology } \\
\text { ward }\end{array}$ & Radiology & $\begin{array}{c}\text { Laboratory } \\
\text { of medical } \\
\text { biochemistry }\end{array}$ & $\begin{array}{c}\text { Operation } \\
\text { department, } \\
\text { thorax }\end{array}$ \\
\hline $\begin{array}{l}\text { Equipment in use during } \\
\text { survey period }\end{array}$ & $24.5 \%$ & $32.3 \%$ & $2.6 \%$ & $51.5 \%$ & $76.2 \%$ & \\
\hline $\begin{array}{l}\text { Turned off manually after } \\
\text { use }\end{array}$ & $93.1 \%$ & $1.6 \%$ & $68.4 \%$ & $29.9 \%$ & $30.1 \%$ & \\
\hline Turned off automatically & $2.0 \%$ & $0.0 \%$ & $0.0 \%$ & $7.2 \%$ & $2.9 \%$ & \\
\hline Stand by & $0.0 \%$ & $17.7 \%$ & $0.0 \%$ & $14.2 \%$ & $15.1 \%$ & \\
\hline $\begin{array}{l}\text { On battery. loading } \\
\text { Must always be turned on }\end{array}$ & $4.9 \%$ & $9.7 \%$ & $18.4 \%$ & $0.9 \%$ & $0.4 \%$ & $6.5 \%$ \\
\hline Not using energy & $0.0 \%$ & $19.4 \%$ & $0.0 \%$ & $1.5 \%$ & $39.3 \%$ & $3.2 \%$ \\
\hline $\begin{array}{l}\text { Runs 24 hours. 7 days a } \\
\text { week }\end{array}$ & $0.0 \%$ & $1.6 \%$ & $0.0 \%$ & $63.1 \%$ & $0.0 \%$ & $45.2 \%$ \\
\hline $\begin{array}{l}\text { Component of other } \\
\text { equipment }\end{array}$ & $0.0 \%$ & $1.6 \%$ & & $0.0 \%$ & $40.2 \%$ & \\
\hline
\end{tabular}

Table 2 shows the great variation among different departments as to how the MTE is actually used. An important observation of the usage-level data is that almost all equipment must be turned off manually by the personnel; virtually no equipment is turned off automatically after a certain time period of inactivity, and only a very small portion of the equipment features a "standby" mode.

\subsection{Measured Electrical Power Consumption by Hospital Departments}

Measured electrical power for peak activity time at a mid-weekday (10 AM to noon), is shown in Table 3 in terms of power per unit floor area. These results confirm the large electrical and heating load caused by equipment. Another interesting result is that full area lighting consumes less than one-third of the power to equipment on an average day. This is in contrast to the standard values used by Norway's building energy code [13], which has power consumption for lighting during working hours the same as equipment.

Table 4 shows the results for the medical biochemistry laboratory. Power readings were taken at 1 minute interval during a typical week (7 days). An extrapolation to energy intensity for an entire year is made for inter-departmental comparison purposes. The result shows a high energy intensity of equipment and lighting in the laboratory area of $113 \mathrm{kBTU} / \mathrm{ft}^{2}$ per year $\left(356 \mathrm{kWh} / \mathrm{m}^{2}\right.$ per year). If electricity to pumps and fans is included, then the electrical energy intensity for laboratory areas can reach 127 $\mathrm{kBTU} / \mathrm{ft}^{2}$ per year $\left(400 \mathrm{kWh} / \mathrm{m}^{2}\right.$ per year).

Measured and extrapolated energy intensity in Table 4 is higher than that calculated based on the users' information about equipment usage levels and our power measurements during peak and off-peak hours. One possible explanation is that lighting in this area is on almost continuously; lighting could not be measured separately on this switchboard. Another explanation for the discrepancy is the high power draw from equipment in standby mode during off-peak hours when lab users reported only $40 \%$ usage rate. This finding indicates high levels of standby power draw in medical laboratory equipment. 
Table 3. Power intensity in for selected hospital departments.

\begin{tabular}{|c|c|c|c|c|c|c|}
\hline Department & $\begin{array}{l}\text { Net floor } \\
\text { area } \mathbf{m}^{2}\end{array}$ & $\begin{array}{c}\text { Imaging } \\
\text { eqpt } \\
\mathrm{W} / \mathbf{m}^{2}\end{array}$ & $\begin{array}{c}\text { Other } \\
\text { eqpt } \\
\text { W/m }\end{array}$ & $\begin{array}{c}\text { Lighting } \\
\mathbf{W} / \mathbf{m}^{2}\end{array}$ & $\begin{array}{l}\text { SUM } \\
\text { W/m }\end{array}$ & $\begin{array}{c}\text { Sum without } \\
\text { imaging eqpt } \\
\mathrm{W} / \mathrm{m}^{2}\end{array}$ \\
\hline Radiology & 921 & 8 & 12 & 12 & 32 & 24 \\
\hline Radiology & 1042 & 91 & 10 & 8 & 109 & 18 \\
\hline $\begin{array}{l}\text { Outpatient } \\
\text { surgical }\end{array}$ & 1350 & 0 & 12 & 13 & 25 & 25 \\
\hline $\begin{array}{l}\text { Outpatient } \\
\text { surgical } \\
\text { Surgical suites }\end{array}$ & 500 & 0 & 23 & 18 & 41 & 41 \\
\hline west & 1014 & 0 & 32 & 8 & 41 & 41 \\
\hline ICU & 567 & 0 & 18 & 7 & 25 & 25 \\
\hline $\begin{array}{l}\text { Surgical suites } \\
\text { east }\end{array}$ & 650 & 0 & 51 & 13 & 64 & 64 \\
\hline $\begin{array}{l}\text { Cardiology } \\
\text { ward } \\
\text { Medical }\end{array}$ & 771 & 0 & 12 & 8 & 20 & 20 \\
\hline $\begin{array}{l}\text { biochemistry* } \\
\text { All }\end{array}$ & 1118 & 0 & $\begin{array}{l}36 \\
35\end{array}$ & $\begin{array}{r}9 \\
10\end{array}$ & $\begin{array}{l}45 \\
47\end{array}$ & $\begin{array}{l}45 \\
33\end{array}$ \\
\hline
\end{tabular}

Table 4. Energy consumption data in medical biochemistry laboratory, collected in one week in 2014.

\begin{tabular}{lccc}
\hline Circuit & $\begin{array}{c}\text { kW (week } \\
\text { avg.) }\end{array}$ & $\mathbf{k W h} / \mathbf{y e a r}$ & $\mathbf{k W h} /\left(\mathbf{m}^{\mathbf{2}}\right.$ year) \\
\hline Priority equipment and lighting & 15 & 129549 & 116 \\
Low priority equipment and lighting & 20 & 170966 & 153 \\
Equipment on UPS circuit* & 11 & 97162 & 87 \\
Sum & $\mathbf{4 6}$ & $\mathbf{3 9 7 6 7 6}$ & $\mathbf{3 5 6}$ \\
\hline
\end{tabular}

*Data logger error; estimate is based on power measurements over a shorter period.

Measuring and logging electrical power over an extended period of time would further reduce some of the uncertainties in our extrapolation. These measurements should also be extended to other functional areas such as normal bed wards.

Based on measured power and reported usage patterns for equipment in all the studied department areas, we estimated the daytime energy intensity of equipment at about $28.5 \mathrm{kBTU} / \mathrm{ft}^{2}$ per year $\left(90 \mathrm{kWh} / \mathrm{m}^{2}\right.$ per year). Note that the energy intensity for 
the entire hospital, including normal bed wards, will be somewhat lower. Norway's building codes feature a standard of only $14.9 \mathrm{kBTU} / \mathrm{ft}^{2}\left(47 \mathrm{kWh} / \mathrm{m}^{2}\right)$ for evaluating energy consumption in hospitals [13]. Based on our results, this figure is too low for many department areas.

\subsection{Analysis of Electrical Energy Consumption by Small MTE (SMTE)}

SMTE such as console-based ultrasound apparatus has typical yearly energy consumption of about $5460 \mathrm{kBTU}(1600 \mathrm{kWh})$ per unit, but there are often more than 20 such units in a medium to large hospital, giving a total yearly consumption comparable to a typical CT device. Patient monitors, laboratory analyzers, chromatograph, centrifuges, incubators, dialysis devices, localized patient heating devices etc. have different power levels and usage patterns drawing an estimated average of about $0.3 \mathrm{~kW}$ electrical power each, for an estimated 5000 hours per year.

\subsection{Electrical Energy Consumption by Medical Imaging Equipment (MIE)}

The Radiology department studied at the Rikshospitalet has several large imaging units with high power ratings. At the time of our measurement, the MIE (CT+MR) in the area consumed $95 \mathrm{~kW}$, for an area of $1042 \mathrm{~m}^{2}$. The calculated energy intensity for MIE is therefore $91 \mathrm{~W} / \mathrm{m}^{2}$. This figure is close to that stated by the Green Guide to Healthcare [14], a LEED-based certification tool, in which imaging process loads are estimated at $86 \mathrm{~W} / \mathrm{m}^{2}$ based on only the treatment area where the equipment is located.

Data of energy consumed by MIE from AHUS showed direct annual electrical energy consumption of about $1774.313 \mathrm{kBTU} /$ year $(520.000 \mathrm{kWh} /$ year$)$. Indirect cooling utility consumption means that the total energy is approximately 2132.588 kBTU/year (625 $000 \mathrm{kWh} /$ year), assuming $80 \%$ recycling of waste heat. Dividing by total hospital area provides total specific energy intensity for large MIE at about 1.6 $\mathrm{kBTU} / \mathrm{ft}^{2}$ per year $\left(5.2 \mathrm{kWh} / \mathrm{m}^{2}\right.$ per year).

Full and standby power drawn by large MIE was studied and published [15] by the authors earlier in the project. Siemens Healthcare, one of the research projects commercial partners, assisted with high resolution power measurements on a range of their own equipment. The results from that investigation showed a high standby power level, especially for the MRI. It has a maximum power of 40 to $45 \mathrm{~kW}$ during the procedure and approximately $17 \mathrm{~kW}$ in standby mode. During night time when the MRI is turned down to the lowest possible level, it still consumes almost $20 \%$ of maximum power, $9 \mathrm{~kW}$ in our case. Another study [10] concluded that the standby power draw dominates energy consumption for medical equipment. In US hospitals the study found annual standby hours for MRI to be $37 \%$, while active usage was only $359 \mathrm{hr}$. /year, which is only $4 \%$ of total time. That study noted that the number of MRI scans is increasing, as is the installed base, at $10 \%$ per year.

\subsection{Cooling and Ventilation Demand}

Waste heat from equipment on a typical workday morning amounts to $3.25 \mathrm{~W} / \mathrm{ft}^{2}$ (35 $\left.\mathrm{W} / \mathrm{m}^{2}\right)$ on average for these areas. Lighting adds another $1 \mathrm{~W} / \mathrm{ft}^{2}\left(11 \mathrm{~W} / \mathrm{m}^{2}\right)$. These areas are usually not located near the periphery of the building; therefore only a small portion 
of the waste heat can be dissipated through the building envelope. Most of the heat remains in the room and must be handled by a combination of ventilation and local room cooling units, all year round. This cooling utility energy must therefore be added to the direct electrical energy consumed by medical equipment to estimate the true energy and climate footprint of all MTE, large and small.

It is important to point out that the heat from peak equipment loads must be combined with loads from sunlight and persons in the room in order to calculate the maximum summer cooling demand.

\section{DISCUSSION}

\subsection{Role of Hospital Guidelines and Product Certifications}

The focus on clinical effectiveness often pushes energy efficiency measures for medical equipment to the background, but energy and climate concerns are now forcing hospital owners, such as the National Health Service (NHS) in England, to set energy performance targets and evaluate lifecycle costs when purchasing hospital equipment [16]. In the US the Northwest Energy Efficiency Alliance has, with the help of Betterbricks, developed equipment purchasing guidelines for hospitals [17]. Green procurement practices and energy certifications such as BREEAM and LEED raise awareness of the energy performance of medical equipment, especially on standby power.

Energy Star certified office equipment products have energy consumption reduced by $30 \%$ to $75 \%$ vs. standard equipment [10]. In Europe, EU Ecodesign [18] directive also regulates the energy performance of building equipment such as lighting, circulation pumps, ventilation fans and water heaters. The directive is now turning its attention to more specialized user equipment such as food-preparing equipment and office imaging equipment, categories that are in wide use in hospitals. Buyers should ask for the highest available 'Ecodesign' certification level. This requirement is especially important considering the growing amount of ICT now offered in patient rooms. It is also important for procurement specifications to call for "power management" functionality in all equipment which draws more than $100 \mathrm{~W}$. This functionality should include standby mode, hibernate mode, fast start up, auto screen shutoff and screen dimming.

\subsection{Recommendations for Hospital Designers, Equipment Suppliers and Hospital Employees}

\subsubsection{Hospital Designers}

Designers are urged to look at the actual usage patterns and make use of the hospital room equipment database to achieve a more optimal sizing for electrical and HVAC cooling systems, down to the room or switchboard level.

Designers of HVAC technical systems should strive to recycle the waste heat generated by medical equipment as much as possible. Water cooled devices have higher heat recovery rate, for example, condenser heat from the ice-water chiller can be easily routed to other applications. The Low Energy Hospital project has new guidelines for heat pump designs [19] which optimize energy production by moving heat between 
areas, and by enabling seasonal storage of excess heat in boreholes, a big advantage for cold climate hospitals. Design "rules of thumb" and potential energy benefits for hospitals using seasonal energy storage are described in Martinez [20].

Waste heat removed by air cooling is more difficult to control and recover. Best practice for ventilation air heat recycling in most building types is with rotating heat wheels, which allow up to $85 \%$ heat recovery. The Low Energy Hospital has published new guidelines which extend the areas that can safely use high efficiency rotating heat wheels [19].

Hospital planners and architects should consider grouping of medical equipment wherever possible to allow more effective, enclosed air-cooling design. Phase Change Materials (PCM) are a promising innovation which can absorb heat emitted from aircooled large MTE and thus avoid shock cooling demands to such rooms.

\subsubsection{Recommendations for Equipment Vendors}

Further product improvement in large imaging devices is needed to reduce scan times, lower standby power level, introduce hibernate functionality, shorten start-up times and expand the use of water cooling instead of air cooling. Suppliers of smaller medical equipment should implement energy-saving measures for the ICT components in their devices by default, especially power-saving modes for screens, and hospital administrators should ensure that such features are tested and running.

Functions which can be handled by networked ICT devices such as printing or storage should be decoupled from the medical equipment and be networked, so that device count may be reduced and energy managed more optimally. Ideally, all large, fixed medical equipment should also be able to join office ICT equipment in a centrally managed networked power management system; this will require close coordination with end-users [10].

Both Siemens and GE Healthcare, two of the largest suppliers of equipment in this category, have stated goals for energy efficiency improvements. GE has previously committed to reducing energy consumption of new ultrasound products by 25 percent by 2012 [21], and they have also set up projects working for equipment energy efficiency [22].

\subsubsection{Recommendations for Hospital Employees}

\subsubsection{Equipment Purchase}

Equipment purchase has been focused on price, functionality and service costs, but not energy. Energy should be a criterion used in lifecycle cost calculations prior to purchase. High power consumption of medical equipment incurs hidden investment costs which are typically not accounted for in lifecycle analysis. Larger dimensions for transformers, uninterruptible power supply and other components of the in-house electrical network are additional costs which can be eliminated with lower power specifications.

It is especially important for procurement specifications to call for "power management" functionality in all equipment which draws more than $100 \mathrm{~W}$. This functionality should include standby mode, hibernate mode, fast start up, auto screen shutoff and screen dimming. When computers are purchased, specify laptops instead of desktop computers and monitors; desktop systems use typically 2 to 3 times as much power. 
Finally, it is important that buyers specify, designers build, and staff use many more low-level energy meters, especially energy meters down at the switchboard level.

\subsubsection{Using Equipment}

The majority of large MIE devices are in use only during day time, at most during a period lasting 10-14 hours per day. With few exceptions (such as MRI), these devices can be entirely shut off outside standby hours, but tend to have long start up times which restrict this energy-saving practice.

Hospital administrators can consider energy monitoring systems (EMS), tied to the central building automation system (BAS) for medical equipment, and network power management systems (PMS) should be implemented for ICT equipment.

Hospital clinical staff should classify equipment which is non-critical and can be part of automatic shut-off routines. Automatically timed electrical power circuits for such non-critical equipment should be introduced, starting in laboratory areas. Automation of electrical sockets, marked with separate color and with LED status indicator, can provide great savings in many areas.

Hospital top administrators should establish energy management practices, with clear accountability and support... In practice, this simply means routines for turning off equipment outside working hours, and enforcement of such practice. Another suggestion is to establish hierarchy where equipment such as printers subordinate to other main equipment will be powered down when the main device is powered down. This will reduce "phantom loads" from standby of ICT equipment, which is about 5\% of the equipment's total energy use [3].

\section{CONCLUSIONS}

This paper presents new research on the electricity consumption of medical equipment in two research hospitals, and compares equipment energy use between different functional areas within a university hospital. The main conclusions from this study are:

- $\quad$ Equipment usage patterns, outside of lab areas, show great variability between night and day as well as weekday and weekend; $40 \%$ of laboratory equipment is left running continuously.

- $\quad$ ICU equipment usage is at times much less than the installed capacity; this requires HVAC design which can perform effectively even at very low part load conditions.

- Even in Norway's leading university hospital, the patient population is not large enough to use more than a fraction of the installed equipment capacity at any given time.

- The majority of large medical imaging equipment devices are in use only during daytime.

- $\quad$ Standard values in the buildings code for average equipment heat loads per unit floor area are lower than measured values, at least for the treatment areas of large modern hospitals.

- $\quad$ Staff generally turns off MTE equipment when not in active use. But MTE with long startup time is generally not turned off, and these units have also high standby power levels as well. 
- $\quad$ Of all the SMTE, very few have power management functions allowing it to be turned off automatically after a specific inactive time. Only a very small portion has a "standby" mode.

- Newer hospitals are not exploiting the potential installing of occupancy for demand control for lighting, heating/cooling and ventilation energy.

- Electrical network design does not separate equipment loads from lighting, making it more difficult to monitor and control energy use.

Some areas for improvement and further study were also identified:

- The hospitals' inventory of their medical equipment does not include average electrical power demand for each item, nor do the hospitals track actual energy consumption at the equipment or switchboard level. Our own data collection was therefore limited to what we could measure at certain places and times, and then extrapolate to higher levels of aggregation based on area data and historic data. Logging of power in all areas, over an extended period of time, would reduce some of the uncertainties in our extrapolations.

- The inventory of MTE included both electrical and non-electrical items. In future works, the non-electrical items should be identified with experts' help, for more energy-relevant equipment population counts.

- $\quad$ Further study is needed to investigate power intensity in normal bed wards and other areas.

\section{ACKNOWLEDGMENTS}

This work is based on the Low Energy Hospitals research project (2010- 2014) funded by the Norwegian Research Council together with public and private sector partners.

\section{CONFLICT OF INTEREST}

The authors are not aware of any conflicts of interests related to this manuscript.

\section{REFERENCES}

[1] Conti PJH, Beamon JA, Napolitano S, Schaal MA, Turnure JamesT, Westfall L. International Energy Outlook 2013. International Energy Outlook. US Energy Information Administration, Washington, 2013, 300. http://www.eia.gov/forecasts/ieo/.

[2] Rohde T, Martinez R, Mysen M. Activity modeling for energy-efficient design of new hospitals. International Journal of Facility Management, 2014, 5(1): 1-16. http://www.ijfm.net/ index.php/ijfm/issue/view/11.

[3] ASHRAE. Advanced Energy Design for Small Hospitals and Healthcare Facilities. R. a. A.-C. E. American Society of Heating, ASHRAE, 2011, 180. https://www.ashrae.org.

[4] Saidur R,Hasanuzzaman M, Mahila TMI, Rahmin NA, Mohammed HA. Chillers energy consumption, energy savings and emission analysis in an institutional building. Energy, 2011.

[5] KwatraSAJ, SachsH. Miscellaneous Energy Loads in Buildings. American Council for Energy Economy, Report number A113, Washington, 2013, 79. http://aceee.org/research-report/a133.

[6] Rohde T. Energieffektive måter å oppnå funksjonskrav for sykehus. SINTEF. Oslo, 2012. www.sintef.no.

[7] Martinez R, Rohde T, Kallmyr K, Horne D, Melby NH, Vårdal J, Jerkø S, Harsem T. Energibruk i sykehus, status over energikrevende funksjonskrav og faktisk forbruk knyttet til bygg og utstyr og muligheter for effektivisering. Low Energy Hospitals, NRC, 2011, 138, www.sintef.no. 
[8] Peters JS, Frank M, Van Clock J, Armstrong A. Electronics and Energy Efficiency: A Plug Load Characterization Study. Research Into Action, Inc. 2010,254. http://www.calmac.org/publications/.

[9] Singer B. Hospital Energy Benchmarking Guidelines. LBNL paper $n r$. 2738E, Lawrence Berkely National Laboratory. 2009, 28. http://energy.lbl.gov/ea/.

[10] McKenny K, Guernsey M, Ponoum R, Rosenfeldt J. Commercial Miscellaneous Loads. Energy Consumption Characterization and Savings Potensial in 2008 by Building Type. U. D. o. E. (DOE). Lexington. TIAX LLC. 2010, 224. http://www.zeroenergycbc.org.

[11] Rohde T. Brukstid for areal i sykehus. Low Energy Hospitals, NRC. SINTEF, Oslo. 2011. www.sintef.no.

[12] Nguyen T A, Aiello M. Energy Intelligent Buildings based on User Activity, A Survey. Energy and Building, 2010, 56: 244-257.

[13] Standard N. Norsk Standard 3031. Standard Norge, 2011. www.standard.no.

[14] GGHC. Green Guide for Healthcare. Version 2.2. 2007. www.gghc.org.

[15] Martinez R, Melby NH, Vårdal J, Hegnedal-Andersen P, Harsem TT. Stricter specification of the energy performance of healthcare equipment can reduce hospital energy consumption. Medical Equipment and Trends in Energy Consumption. 4th European Conference on Healthcare Engineering, Paris, Norconsult as and Siemens Healthcare a. 2011.

[16] Agency PS. Protocol Energy Efficiency Assessment for Electrical Medical Devices, NHS Purchasing and Supply Agency,CEP08037,2009. http://www.sduhealth.org.uk.

[17] Betterbricks. Energy Efficient Equipment Purchasing Guidelines for Hospitals. T. C. I. o. t. N. E. E. Alliance, Betterbricks. Version 1, 2010. http://www.betterbricks.com.

[18] COUNCIL TEPAT. Establishing a framework for the setting of ecodesign requirements for energyrelated products. DIRECTIVE 2009/125/EC. E. EU. Official Journal of the European Union EU, Comission: 24, 2009. http://eur-lex.europa.eu.

[19] Harsem TT. Veiledere FOU-prosjekt lavenergi sykehus. Low Energy Hospital Project, NRC, Sandvika, 2014.

[20] Martinez R. Balancing Act - Using Hybrid Heat Sources to Avoid Permafrost and Optimize Heat Pump Systems in Cold Climate Hospitals. 7th International Cold Climate HVAC Conference. Calgary, Alberta, Canada, Norconsult as, 2012.

[21] GE Healthcare and Medical Device Industry Commit to Reducing Energy Use of Ultrasound Products, GE,2010. http://www.gecitizenship.com.

[22] LEED. Medical and process Equipment Efficiency. U. D. o. Energy, LEED Pilot Credit Library,2010. http://www.usgbc.org. 



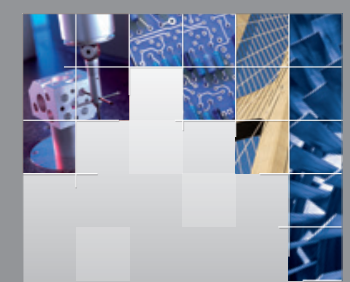

\section{Enfincering}
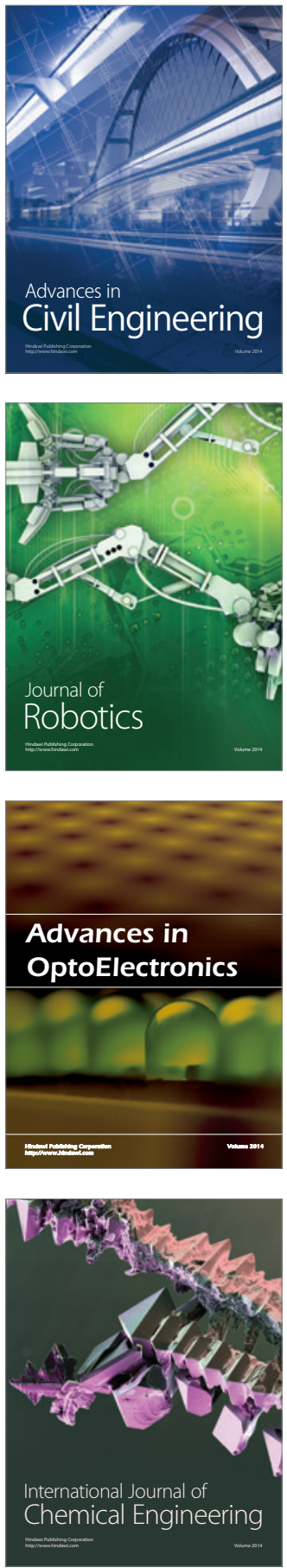

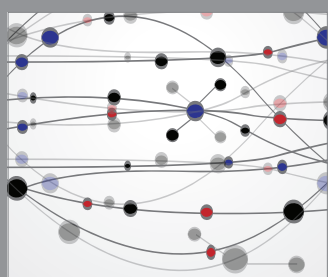

The Scientific World Journal

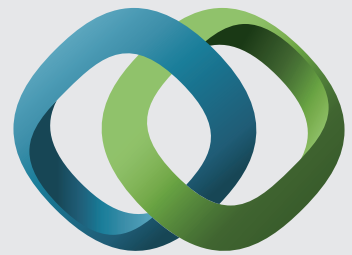

\section{Hindawi}

Submit your manuscripts at

http://www.hindawi.com
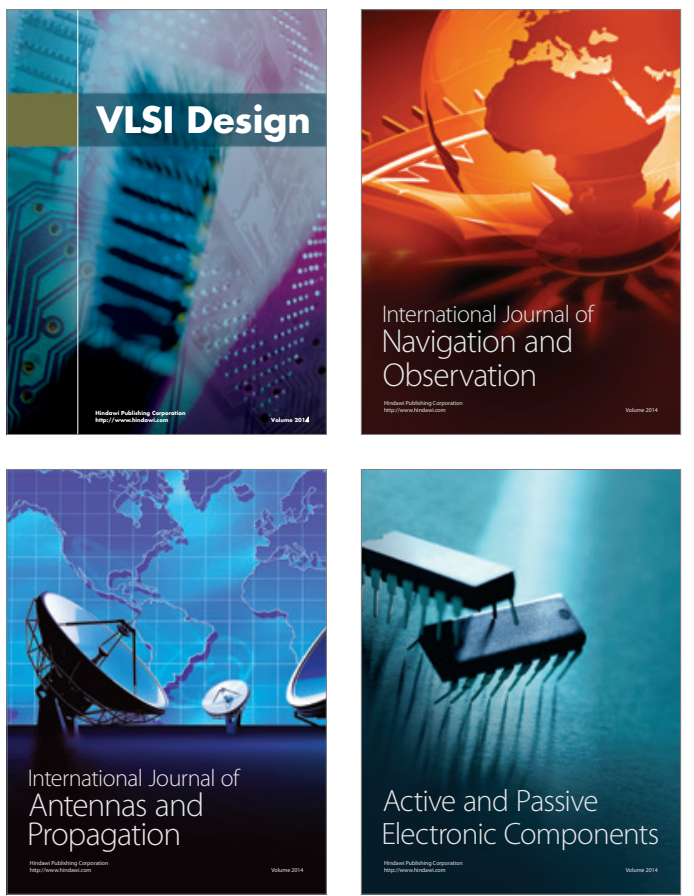
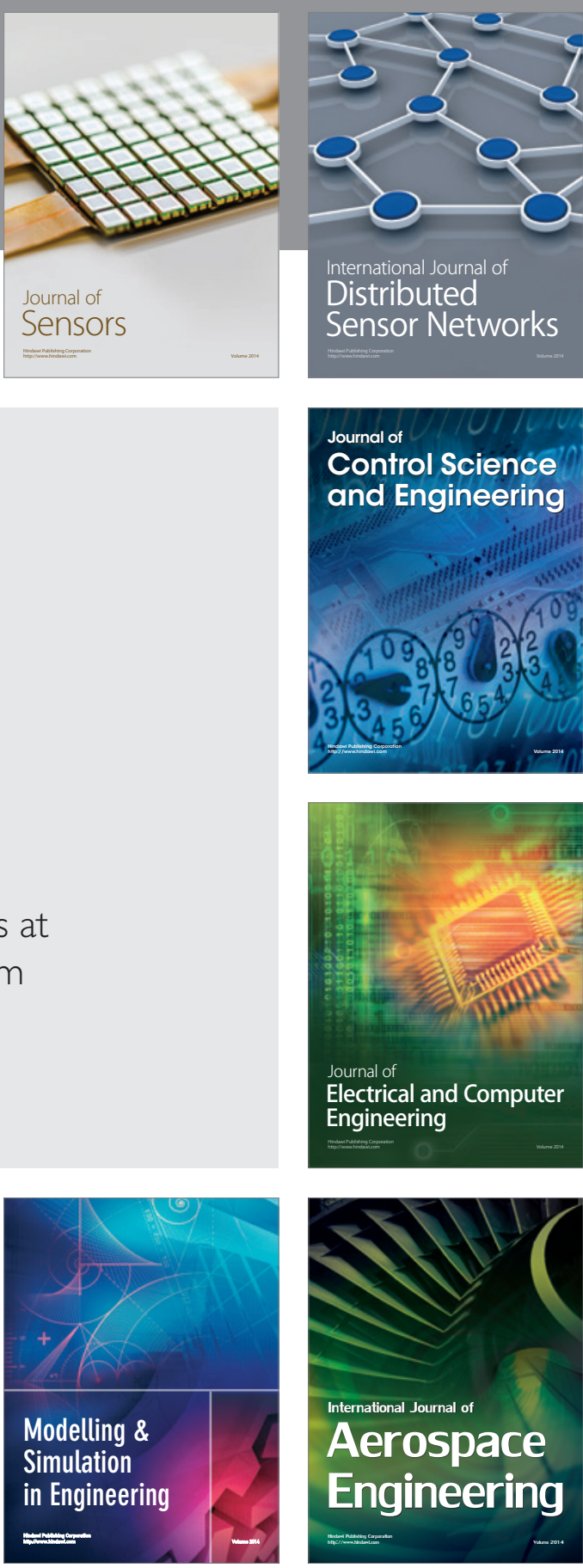

International Journal of

Distributed

Sensor Networks

Journal of

Control Science

and Engineering
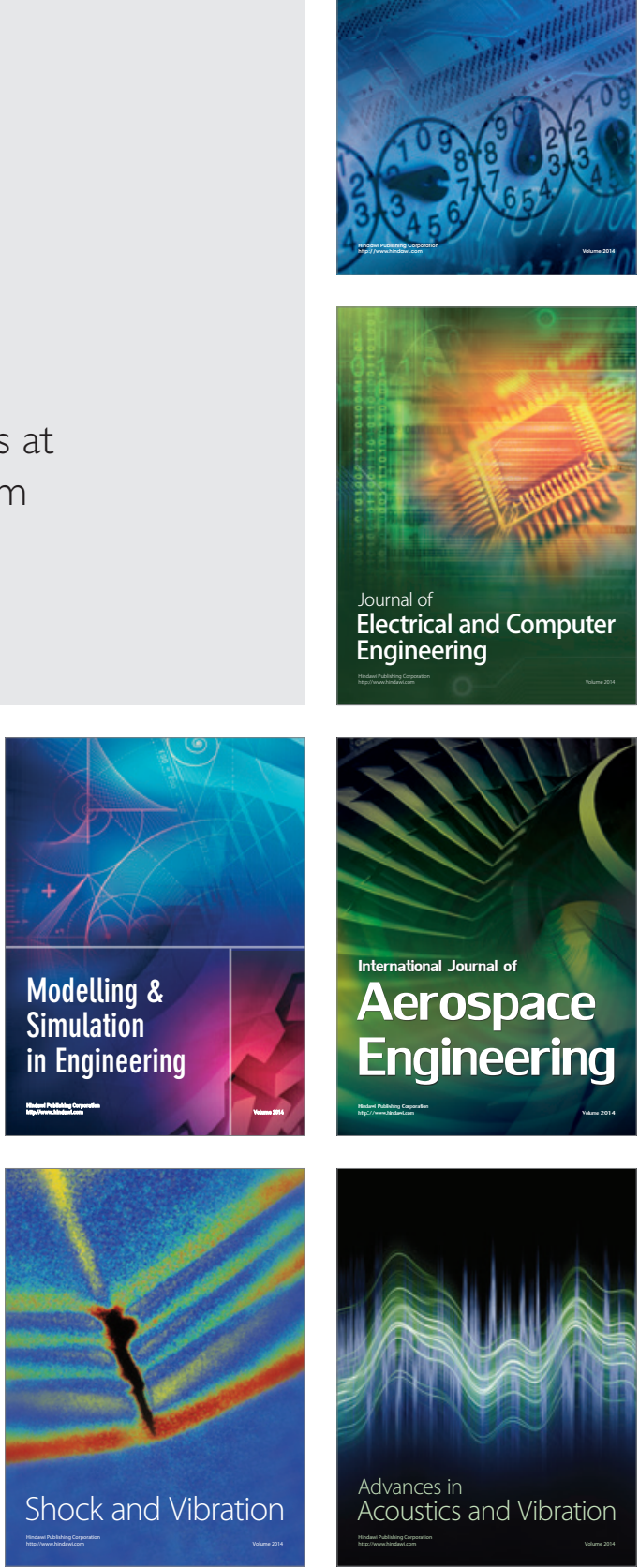